\title{
Detailed Structural and Morphological Characterization of InGaN Thin Films Grown by RF Magnetron Sputtering with Various Substrate Temperature
}

\author{
Asim Mantarci* \\ Department of Opticianry, Muş Alparslan University, Muş, Turkey \\ *asimmantarci@gmail.com \\ Received: 23 November 2018 \\ Accepted: 09 May 2019 \\ DOI: $10.18466 /$ cbayarfbe.486961
}

\begin{abstract}
Indium Gallium Nitride (InGaN) thin film was grown on the GaN $/ p-S i$ substrate using an RF magnetron sputter under condition of different substrate temperatures. Various experimental measurements were taken to comprehend effects of substrate temperature on the structure of thin film and results were analyzed. Grazing mode of XRD results confirmed that InGaN thin film has a hexagonal structure with (002) plane for $500^{\circ} \mathrm{C}$ and $600{ }^{\circ} \mathrm{C}$ substrate temperature. It was seen that structural parameters of thin film show a change with substrate temperature change. Reasons were discussed. Strain and stress values in InGaN thin film were calculated from experimental results and it was found that all thin film has compressive stress. Morphological parameters of thin film were measured by AFM and it was understood that these properties are varied by changing substrate temperature. Also, growth mode of some thin film was obtained to be layer-plus-island mode (Stranski-Krastanov growth mode), others was obtained to be layer by layer growth mode (Frank van der Merwe mode). SEM evaluation gives that increasing substrate temperature worsened the surface structure of InGaN thin film; it is compatible with and supports XRD results. Compositional values in InGaN thin film were found from XPS analysis. In addition to our material, carbon and oxygen have also been obtained from XPS results, as expected. Detailed morphological and structural properties of InGaN thin films have been seen to change with changing substrate temperature and we believe this plays an important role in production of $\operatorname{InGaN}$ based optoelectronic devices.
\end{abstract}

Keywords: InGaN, thin film technology, RF magnetron sputtering, substrate temperature.

\section{Introduction}

One of the material groups that play an crucial role in application and development of optoelectronic, high temperature electronics [1] is known as III-nitrite semiconductors [2, 3] with direct-wide band gap $~ 0.65-6.2 \mathrm{eV}$. InGaN (Indium Gallium Nitride), one of the most important nitride group materials, has physical properties that are important for photovoltaic device technology. These properties are followings; high absorption coefficient, good resistance of irradiance, having direct-band gap. Due to these advantageous properties, it is used in laser diodes, in tunnel field effect transistor [4], in Light Emitting Diode (LED) [5, 6], in tandem solar cell, in photonic integration, in electroluminescent devices. To produce high quality InGaN thin film; many techniques can be benefitted; Sputtering [7], Metal Organic Chemical Vapor Deposition (MOCVD), Thermionic Vacuum Arc (TVA) [8], catalyst-assisted growth, Atomic Layer Deposition (ALD). Many InGaN thin film research grown by sputtering method have been published in the past and can be found. Qixin Guo et al. studied that InGaN thin film was produced onto $S i$ substrate using reactive magnetron sputter. RF power effects on indium composition in film was researched. They found that it can be controlled by RF power. Also, they used the technique that has advantage such as low cost with high quality deposition. Dong-Hau Kuo et al. investigated that $I n_{x} G a_{1-x} N$ with $m g$ doped was grown onto Si substrate using reactive sputter. They produced $p-$ $I n_{0.05} G a_{0.95} \mathrm{~N} / \mathrm{n}-\mathrm{GaN}$ junction diode with $2.7 \times$ $10^{-6} A$ (current of leakage), $1.8 \mathrm{~V}$ (breakdown voltage), $30-110 \Omega$ ( varies series voltages). They used norde model to calculate diode parameters and concluded that the diodes have good physical parameters [9]. Thi Tran Anh Tuan et al. reported that $n-\operatorname{InGaN} / p-S i$ heterojunction diode was produced with magnetron sputter. They detailed investigated that temperature effects on electrical parameters on diode produced. Diodes that they produced has avantage usable in cost-effective power electronics [10].

In this study, the effects of substrate temperature on growth mechanism, structural and morphological properties of InGaN thin films deposited on $G a N / p-S i$ substrates by means of RF magnetron sputtering were 
examined. The novelty aspect of this study is based on two main factors. One is that in our detailed literature review (as mentioned above), although there has been many publications related to InGaN thin film growth and characterization, the impacts of substrate temperature effects on growth and characterization of InGaN thin films onto $G a N / p-S i$ substrate with RF magnetron sputtering was not studied. Other is that the growth technique (RF magnetron sputtering) which we used in this study has some advantages such as safety, low cost and shorter growth time when compared to other techniques (e.g. Molecular Beam Epitaxy). These plus aspects are important for both researchers and industry.

\section{Materials and Methods}

\subsection{Growth of InGaN thin film}

Thin film growth was done with Radio Frequency (RF) magnetron sputtering, which is one of physical deposition techniques. Basically, the mechanism of this system is plasma based deposition operation in which energetic ions accelerate towards the target. Ions hit the target; atoms have sputtered from surface of target. These atoms have moved towards surface of substrate, and thin film was formed with providing condensation there. As Direct Current and Radio Frequency mode, there are two modes. Radio Frequency sputter method was used at non-conductive material; DC sputtering method was used at conductive material. Radio Frequency magnetron sputter method has advantage that magnets better has ionized material in electric and magnetic field and has allowed material to pass into plasma form. It was benefitted Radio Frequency magnetron sputter (PVD-Midas 3M model (System number: VK-1601-2)) to grow InGaN thin film at DAYTAM (Center of East Anatolian High-Technology Research and Application). Technical parameters of the machine we use are given follows; ultimate vacuum pressure is $\leq 5 \times 10^{-8}$ Torr, substrate rotation is $3-$ $30 \mathrm{rpm}$; substrate size is about $4-8 \mathrm{inch}$ diameter, control is provided as fully automatic, substrate heating maximum is $800^{\circ} \mathrm{C}$. To remove defects (oxygen and other gases), it was used and a mechanical pump, a turbo molecular pump mounted on our system. We purchased $I n_{0.2} G a_{0.8} \mathrm{~N}$ as target with purity $99.95 \%$ (Lot no: 22709-16-01) from ACI Alloys, Inc. The GaN/p-Si thin film we used as substrate material was previously produced and published as an article [3]. Respectively, the following steps were followed before growth. Substrates are cleaned using $\left(\mathrm{NH}_{4}\right)_{2} \mathrm{~S}$ treatments ( $\left(\mathrm{NH}_{4}\right)_{2} \mathrm{~S}$ for $1 \mathrm{~min}$., DI (Deionize Water) of 60 second, dry of $N_{2}$, detailed cleaning process summarized to referred [11] ). After that; substrates were placed in the growth plate and left into the sputter machine. To research substrate temperature effects, $500{ }^{\circ} \mathrm{C}, 600{ }^{\circ} \mathrm{C}$, $700{ }^{\circ} \mathrm{C}$ substrate temperature were applied to system at each separate experiment. Detailed growth conditions of InGaN thin films for different substrate temperature were given in Table 1. Schematic view of structure of thin film was given in Figure 1. For all of growth, cleaning and preparation processes, we used ISO 3 (International Organization for Standardization) class cleaning room at DAYTAM.

\subsection{Characterization of InGaN thin film}

In order to characterize the produced thin films, following experimental methods were conducted; Atomic Force Microscopy (AFM), X-ray Diffraction (XRD), X-ray Photoelectron Spectroscopy (XPS), Field Emission Scanning Electron Microscopy (FE-SEM), Surface Profile Metrology P7 (KLA-tensor). PANalytical X-ray Diffraction System (Empyrean model) has been examined ( $C u K_{\alpha}=1.5406 A^{\circ}$ ) to look at structure InGaN thin films. Compositional properties of material were operated by $\mathrm{X}$ ray Photoelectron Spectroscopy (XPS). Morphological analysis of InGaN thin film was studied using AFM-500II. Field-Emission Scanning Electron Microscopy (FE-SEM) (Zeiss Sigma300model) was investigated to analyze morphological and surface of thin film. InGaN thin film's thicknesses was measured using Surface Profile Metrology P7 (KLA-tensor). Also, we measured thicknesses of thin film at RF magnetron sputter sensor. By comparing these values, calibration of RF magnetron sputter sensor value were done with profile meter. InGaN thin film thickness was $120 \mathrm{~nm}$ for all substrate temperatures. All experimental measurements were obtained from advanced spectroscopy laboratory at DAYTAM (Center of East-Anatolian High-Technology Research, Application).

\section{Results and Discussion \\ 3.1. XRD analysis}

Figure 2 gives Grazing mode of XRD spectrums of InGaN $/ G a N / p-S i$ thin film for different substrate temperature. It was observed peaks of $33.03^{\circ}, 32.97^{\circ}$ for $500^{\circ} \mathrm{C}, 600^{\circ} \mathrm{C}$ substrate temperature, which are corresponded to (002) planes of hexagonal InGaN (PDF code: 98-018-1363 from Inorganic Crystal Structure Database (ICSD). And also, we detected no peak for $700^{\circ} \mathrm{C}$ substrate temperature growth condition, showing in Figure 2. This result proves that our film structure is amorphous. XRD peaks of GaN and of $p-S i$ already published in our previous work [3]. It was seen that peaks of $33.15^{\circ}$ were shifted to $33.03^{\circ}$ and $32.97^{\circ}$ for (002) plane of hexagonal InGaN. It was thought that these shifts are caused by impurities and defects in the film during growth. With the help of Scherer's relation, grain sizes of InGaN thin films can be found; $D=\frac{K \lambda}{\beta \operatorname{Cos} \theta}$

$K=0.9$ shows constant, , $\theta$ shows Bragg's diffraction angle, $\lambda$ shows the $\mathrm{X}$-ray wavelength, $\beta$ shows full width of half maximum intensity. Grain sizes $(D)$ of our film was computed with highest peak intensity. Structural parameters of InGaN/GaN/p-Si thin film using RF magnetron sputter at different substrate temperature were given in Table 2. XRD result proves that by increasing 
the substrate temperature from $500{ }^{\circ} \mathrm{C}$ to $600{ }^{\circ} \mathrm{C}, \mathrm{FWHM}$ value has increased and grain size of the thin film has decreased. It has resulted in deterioration in crystal quality of InGaN thin film. When substrate temperature was $700{ }^{\circ} \mathrm{C}$ degrees beyond $600{ }^{\circ} \mathrm{C}$, the thin film structure starts to deteriorate and becomes amorphous. As a result; it was understood structure of InGaN thin films with increment of substrate temperature has deteriorated. When reasons of this deterioration were examined, the following analysis was reached. Increase of substrate temperature mainly affects increment of two competing factors. One is that increasing substrate temperature increases mobility of atoms. Other factor is that increasing substrate temperature increases grainlike, island structures on thin film. Which of these factors is dominant is related to the deterioration or development of the structure of the film. In our thin film, increasing substrate temperature predominantly increases of grainlike, island structures on thin film. Therefore, it was concluded that our thin film has deteriorated structurally. It was understood that better crystallizing in structure of InGaN $/ G a N / p-S i$ thin film has been achieved under $500{ }^{\circ} \mathrm{C}$ substrate temperature and worse crystallizing (which means amorphous phase) in structure of InGaN/ $\mathrm{GaN} / p-S i$ thin film has been achieved under $700{ }^{\circ} \mathrm{C}$ substrate temperature. By using Bragg equation (formula 2) and formula 3, lattice parameters $c$ and $a$ can be calculated;

$$
\begin{aligned}
d_{h k l} & =\frac{\lambda}{\left(2 \sin \theta_{h k l}\right)} \\
\frac{1}{d_{h k l}} & =\sqrt{\frac{4}{3}\left(\frac{h^{2}+h \cdot k+k^{2}}{a^{2}}\right)+\frac{l^{2}}{c^{2}}}
\end{aligned}
$$

$d$ refers space of lattice, $\lambda$ refers wavelength of $X$-ray source, $h k l$ refers miller indices, $\theta_{h k l}$ refers reflection angle from $h k l$ miller indices, $a$ and $c$ refer lattice parameters at hexagonal materials. Table 2 gives all of lattice parameters of InGaN thin film. By using formula (4), out-of-plane strain and in-plane strain is computed;

$\varepsilon_{c}=\left(c-c_{0}\right) / c_{0}, \quad \varepsilon_{a}=\left(a-a_{0}\right) / a_{0}$

$\varepsilon_{c}$ and $\varepsilon_{a}$ means out-of-plane strain and in-plane strain, $c_{0}$ and $a_{0}$ lattice parameters of GaN stress free ( $c_{0}=$ $0.5399 \mathrm{~nm}, a_{0}=0.33300 \mathrm{~nm}$ [12] ). Out of plane strain $\left(\varepsilon_{c}\right)$ of InGaN thin film for (002) plane were found as $0.0037,0.0002$ under condition of $500{ }^{\circ} \mathrm{C}$, $600^{\circ} \mathrm{C}$ substrate temperature. In-plane strain $\left(\varepsilon_{a}\right)$ of InGaN thin film for (002) plane has been determined to be $-0.0034,-0.0069$, for $500{ }^{\circ} \mathrm{C}, 600^{\circ} \mathrm{C}$ substrate temperature growth condition. The minus sign means that the value of the lattice parameters is reduced and this indicates compressive stress. Strain and stress values in
InGaN/GaN/p-Si thin films for different substrate temperature were given in Table 3 . With the help of formula (5) and formula (6) [13], in-plane stress $\left(\sigma_{a}\right)$ of InGaN thin film can be calculated;

$\frac{\varepsilon_{c}}{\varepsilon_{a}}=-\frac{2 \mathrm{v}}{(1-\mathrm{v})}$

$\varepsilon_{c}=-E^{-1} \sigma_{a} 2 \mathrm{v}$

$\varepsilon_{c}$ and $\varepsilon_{a}$ refer out-of-plane strain and in-plane strain, $\mathrm{v}$ shows poisson ratio, $E(375.8 \mathrm{GPa})$ indicates Young Modulus of InGaN (from reported study of [14]). In plane stress of $\left(\sigma_{a}\right) \operatorname{InGaN}$ thin film for $(002)$ plane was found to be $-1.97,-2.55$, under condition of $500{ }^{\circ} \mathrm{C}, 600^{\circ} \mathrm{C}$ substrate temperature. XRD results prove that thin films have compressive stress. When the causes of this stress in thin film are investigated, the following evaluations can be reached. The three main factors are evaluated to cause stress. One is that lattice parameters difference between GaN and InGaN. Stress in InGaN thin film will happen due to the difference in the lattice parameters while growing onto $\mathrm{GaN} / p-\mathrm{Si}$.Other factor is that thermal expansion coefficients difference between $G a N$ and $I n G a N$. Thin film is expanded in ratio of thermal expansion coefficient because thermal constants of them are different, when film is cooled down; stress is occurred in thin film. Another factor is that stress in thin film has originated from impurity and defect in film during growth. In the past studies, it has been reported that the stress in thin film is important when producing optoelectronic devices based on thin film. Compressive stress reasons separation layer in device and buckling, eventually short circuit problem in devices [15]. It has been emphasized that it is important to produce structurally better quality thin films to obtain a better quality optoelectronic device based on thin film. As a result, the change in crystal structure of InGaN thin films were detected by changing the substrate temperature and substrate temperature was found playing an important role in production of better quality thin film.

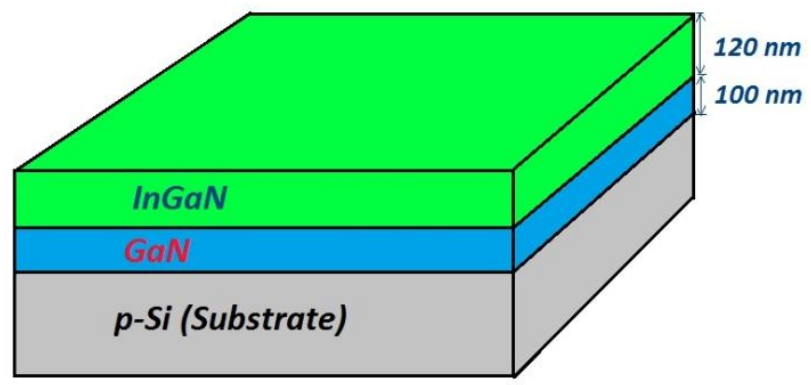

Figure 1. Schematic view of structure of thin film.

Table 1. Growth conditions of InGaN $/ G a N / p-S i$ thin films for different substrate temperature. 
Celal Bayar University Journal of Science

Volume 15, Issue 2, 2019, p 151-160

Doi: $10.18466 /$ cbayarfbe.486961

A. Mantarc1

\begin{tabular}{cccccccc}
\hline $\begin{array}{c}\text { Substrate } \\
\text { Temperature } \\
\left(C^{\circ}\right)\end{array}$ & $\begin{array}{c}\text { Argon } \\
\text { Flow Rate } \\
(s c c m)\end{array}$ & $\begin{array}{c}\text { Nitrogen } \\
\text { Flow Rate } \\
(s c c m)\end{array}$ & $\begin{array}{c}\text { RF } \\
\text { Power } \\
(\text { Watt })\end{array}$ & $\begin{array}{c}\text { Base } \\
\text { Pressure } \\
(k P a)\end{array}$ & $\begin{array}{c}\text { Working } \\
\text { Pressure } \\
(\mathrm{kPa})\end{array}$ & $\begin{array}{c}\text { Growth } \\
\text { Time } \\
(\mathrm{min} .)\end{array}$ & $\begin{array}{c}\text { Film' } \\
\text { Thickness } \\
(\mathrm{nm})\end{array}$ \\
\hline 500 & 100 & 1 & 100 & $\begin{array}{l}1.11 \\
\times 10^{-7}\end{array}$ & $\begin{array}{l}1.13 \\
\times 10^{-3}\end{array}$ & 120 & 120 \\
600 & 100 & 1 & 100 & $\begin{array}{l}1.17 \\
\times 10^{-7}\end{array}$ & $\begin{array}{l}1.09 \\
\times 10^{-3}\end{array}$ & 80 & 120 \\
700 & 100 & 1 & 100 & $\begin{array}{l}0.85 \\
\times 10^{-7}\end{array}$ & $\begin{array}{l}1.10 \\
\times 10^{-3}\end{array}$ & 95 & 120 \\
\hline
\end{tabular}

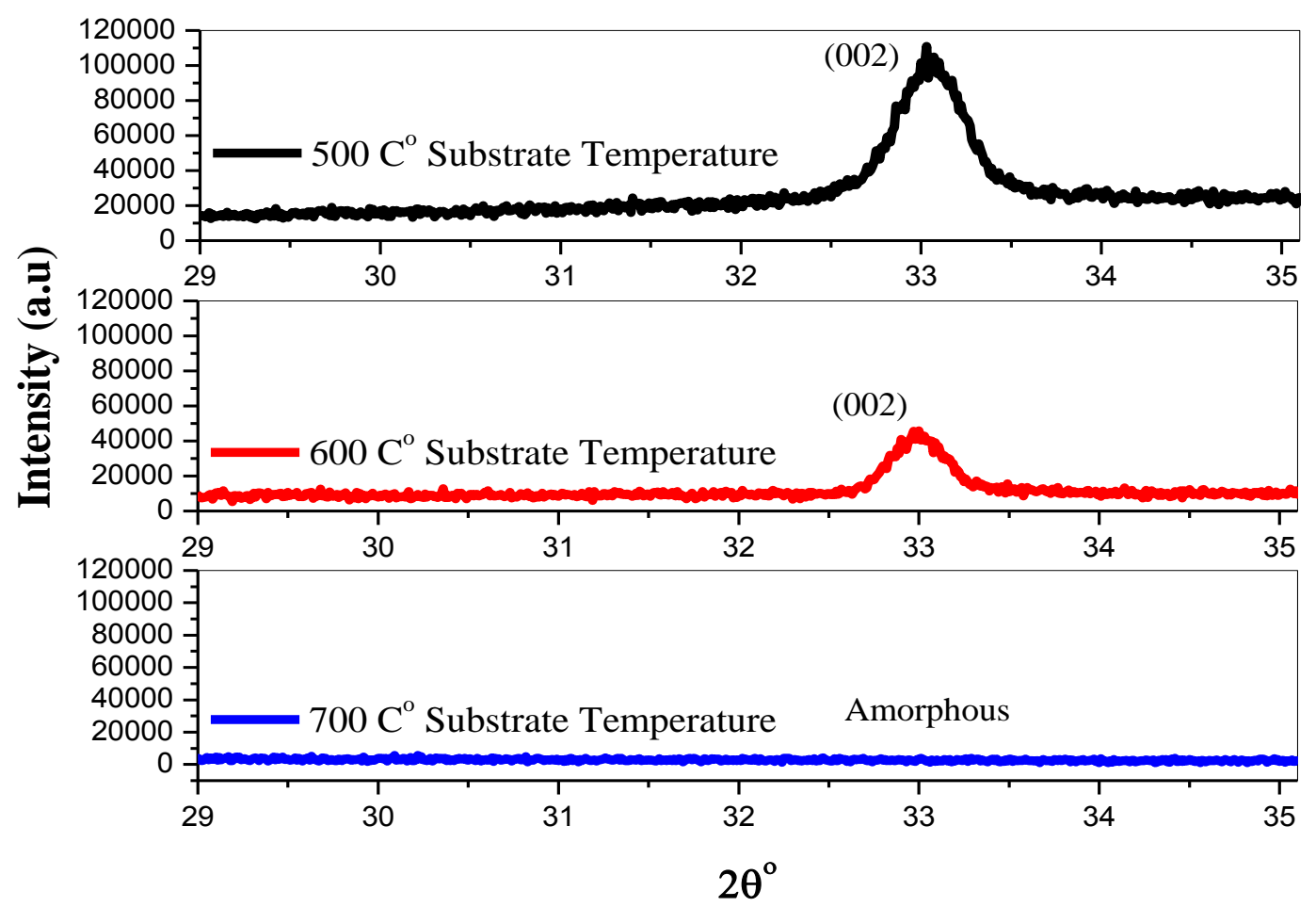

Figure 2. Grazing mode of XRD spectrums of $I n G a N / G a N / p-S i$ thin film for different substrate temperature.

Table 2. Structural parameters of InGaN/GaN/p - Si thin film using RF magnetron sputter at different substrate temperature.

\begin{tabular}{|c|c|c|c|c|c|c|c|c|c|}
\hline $\begin{array}{c}\text { Substrate } \\
\text { Temperature } \\
\left(C^{\circ}\right)\end{array}$ & $(\boldsymbol{h} \boldsymbol{k} \boldsymbol{l})$ & $\begin{array}{c}\text { FWHM } \\
\left({ }^{\circ}\right)\end{array}$ & $\begin{array}{c}2 \theta \\
\text { (Observed) } \\
\left(^{\circ}\right)\end{array}$ & $\begin{array}{l}2 \theta \\
(*) \\
\left(^{\circ}\right)\end{array}$ & $\begin{array}{c}\text { d- } \\
\text { value } \\
(\AA)\end{array}$ & $\begin{array}{l}\text { d-value } \\
(*)(\AA)\end{array}$ & $\begin{array}{c}\text { Lattice } \\
\text { parameter } \\
(*)(\AA)\end{array}$ & $\begin{array}{c}\text { Lattice } \\
\text { parameter }(\AA)\end{array}$ & $\begin{array}{c}\text { Grain sizes } \\
\text { (D) }(n m)\end{array}$ \\
\hline 500 & $(002)$ & 0.336 & 33.03 & 33.15 & 2.7097 & 2.6995 & $\begin{array}{l}a \\
=3.3300 \\
c \\
=5.3990\end{array}$ & $\begin{array}{l}a=3.3186 \\
c=5.4194\end{array}$ & 24.95 \\
\hline 600 & $(002)$ & 0.461 & 32.97 & 33.15 & 2.7002 & 2.6995 & $\begin{array}{l}a \\
=3.3300 \\
c \\
=5.3990\end{array}$ & $\begin{array}{l}a=3.3070 \\
c=5.4004\end{array}$ & 18.19 \\
\hline $700^{\&}$ & - & - & - & - & - & - & - & - & - \\
\hline
\end{tabular}

*(Standard values from ICSD code of PDF: 98-018-1363); $\quad \&$ amorphous structure 
Table 3. Strain and stress in InGaN/GaN/p - Si thin films for different substrate temperature.

\begin{tabular}{cccccc}
\hline $\begin{array}{c}\text { Substrate } \\
\text { Temperature } \\
\left(C^{\circ}\right)\end{array}$ & $(\mathbf{h k l})$ & $\begin{array}{c}\text { Out-of-plane } \\
\text { strains } \\
\left(\boldsymbol{\varepsilon}_{\boldsymbol{c}}\right)\end{array}$ & $\begin{array}{c}\text { In-plane } \\
\text { strains } \\
\left(\boldsymbol{\varepsilon}_{\boldsymbol{a}}\right)\end{array}$ & $\begin{array}{c}\text { In-plane } \\
\text { stresses } \\
\left(\boldsymbol{\sigma}_{\boldsymbol{a}}\right)(G P a)\end{array}$ & Type of stress \\
\hline 500 & $(002)$ & 0.0037 & -0.0034 & -1.97 & Compressive \\
\hline 600 & $(002)$ & 0.0002 & -0.0069 & -2.55 & Compressive \\
\hline 700 & $(002)$ & - & - & - & - \\
\hline
\end{tabular}

\subsection{AFM analysis}

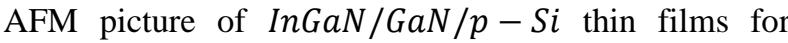
different substrate temperature growth condition is displayed in Figure 3. The maximum height of InGaN thin film were measured to be $5.498 \mathrm{~nm}$ (the highest value) corresponding to $500{ }^{\circ} \mathrm{C}$ substrate temperature. The maximum height of InGaN were measured to be $1.204 \mathrm{~nm}$ (lowest value) related to $600{ }^{\circ} \mathrm{C}$ substrate temperature. Maximum depth $\left(R_{v}\right)$ of InGaN thin films were obtained to be $2.712 \mathrm{~nm}$ (lowest value) related to $600{ }^{\circ} \mathrm{C}$ substrate temperature. Maximum depth $\left(R_{v}\right)$ of InGaN thin films were attained as $5.455 \mathrm{~nm}$ (highest value) corresponding to $500{ }^{\circ} \mathrm{C}$ substrate temperature. We had highest average absolute slope $(\Delta a)$ as $16.22^{\circ}$ related to $700{ }^{\circ} \mathrm{C}$ substrate temperature. from AFM measurements. The lowest average absolute slope has been measured to be $12.59^{\circ}$ corresponding to $600{ }^{\circ} \mathrm{C}$ substrate temperature. The highest root mean square (RMS) roughness were measured as $2.220 \mathrm{~nm}$ corresponding to $500{ }^{\circ} \mathrm{C}$ substrate temperature, whereas the lowest root mean square (RMS) roughness were measured as $0.856 \mathrm{~nm}$ corresponding to $600{ }^{\circ} \mathrm{C}$ substrate temperature, as given in Figure 4. Detailed morphological parameters of InGaN thin film is given

in Table 4. Increased substrate temperature from $500{ }^{\circ} \mathrm{C}$ to $600{ }^{\circ} \mathrm{C}$ leads to smoother surface with $1.067 \mathrm{~nm}$, displaying that surface of InGaN thin film grown as Frank-van der Merwe mode (layer by layer growth mode). But; increased substrate temperature from $600{ }^{\circ} \mathrm{C}$ to $700^{\circ} \mathrm{C}$ has resulted in rougher surface with
$0.789 \mathrm{~nm}$, displaying that surface of $\operatorname{InGaN}$ thin film grown as Stranski-Krastanov mode (layer plus island growth mode). Highest average roughness were found as $1.772 \mathrm{~nm}$ related to $500{ }^{\circ} \mathrm{C}$ substrate temperature, but lowest average roughness was found to be $0.705 \mathrm{~nm}$ related to $600^{\circ} \mathrm{C}$ substrate temperature. It was seen that increasing substrate temperature from $500^{\circ} \mathrm{C}$ to $600^{\circ} \mathrm{C}$ give rise to decrease in average roughness of thin film, while increasing substrate temperature from $600^{\circ} \mathrm{C}$ to $700^{\circ} \mathrm{C}$ give rise to increase in average roughness of thin films. In thin film-based optoelectronic device applications, in some cases, high surface roughness and in some cases low surface roughness is preferred. One study shows rough surface is contributed to improvement of light extraction of thin film LED because of increased light extraction ability of micro rough surface which implies a roughness role on optical properties of materials [16]. On the other hand; different study shows increasing roughness of interface for the AlGaN/GaN hetero-structure leads to a reduction in mobility and that interface roughness role on the electrical properties of the device has emerged [17]. It should be noted that it is important to decide which device you prefer and which features of this device when you want to select a rougher or smoother surface for thin film surface property. Except for $700{ }^{\circ} \mathrm{C}$ substrate temperature growth condition, AFM figure shows periodic arrangement of grain with almost homogeneous, nano-structured InGaN thin films surface. We concluded that morphological parameters of InGaN thin film show non-linear variation with substrate temperature. 
Celal Bayar University Journal of Science

Volume 15, Issue 2, 2019, p 151-160

Doi: $10.18466 /$ cbayarfbe.486961

A. Mantarc1
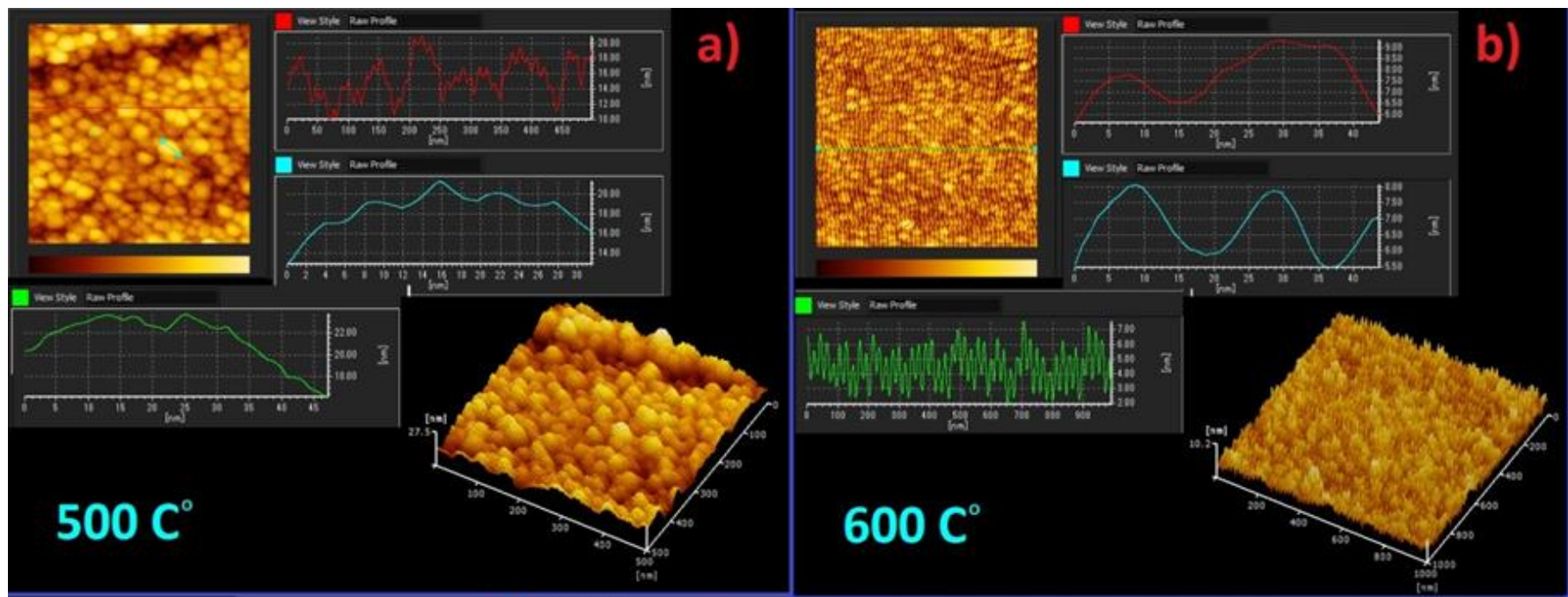

c)
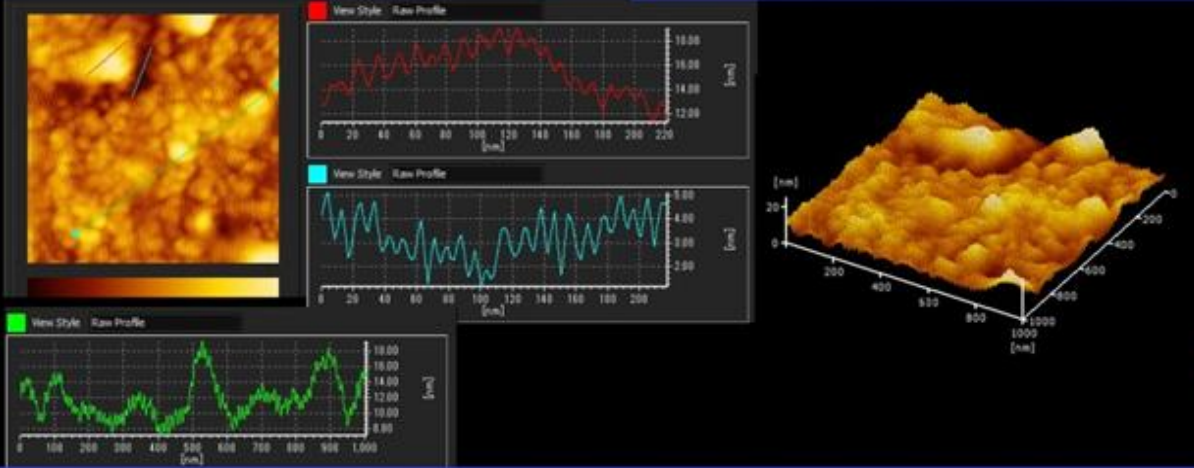

$700 C^{\circ}$

Figure 3. AFM picture of InGaN /GaN/p - Si thin films for a) $500^{\circ} \mathrm{C}$ b) $600{ }^{\circ} \mathrm{C} \mathrm{c} \mathrm{)} 700{ }^{\circ} \mathrm{C}$ substrate temperature growth condition.

Table 4. Morphological parameters of $\operatorname{InGaN} / G a N / p-S i$ thin films for different substrate temperature.

\begin{tabular}{cccccc}
\hline $\begin{array}{c}\text { Substrate } \\
\text { Temperature } \\
\left(C^{\circ}\right)\end{array}$ & $\begin{array}{c}\text { Average } \\
\text { Roughness } \\
\left(R_{a}\right)(n m)\end{array}$ & $\begin{array}{c}\text { Maximum peak } \\
\text { height } \\
\left(R_{p}\right)(n m)\end{array}$ & $\begin{array}{c}\text { Average } \\
\text { absolute slope } \\
(\Delta a)\left({ }^{\circ}\right)\end{array}$ & $\begin{array}{c}\text { Maximum } \\
\text { valley } \\
\text { depth }\left(R_{v}\right)(n m)\end{array}$ & $\begin{array}{c}\text { Root Mean Square } \\
\text { Roughness }\left(R_{q}\right)(n m)\end{array}$ \\
\hline 500 & 1.772 & 5.498 & 15.58 & 5.455 & 2.220 \\
600 & 0.705 & 1.204 & 12.59 & 2.712 & 0.856 \\
700 & 1.494 & 3.605 & 16.22 & 4.026 & 1.768 \\
\hline
\end{tabular}




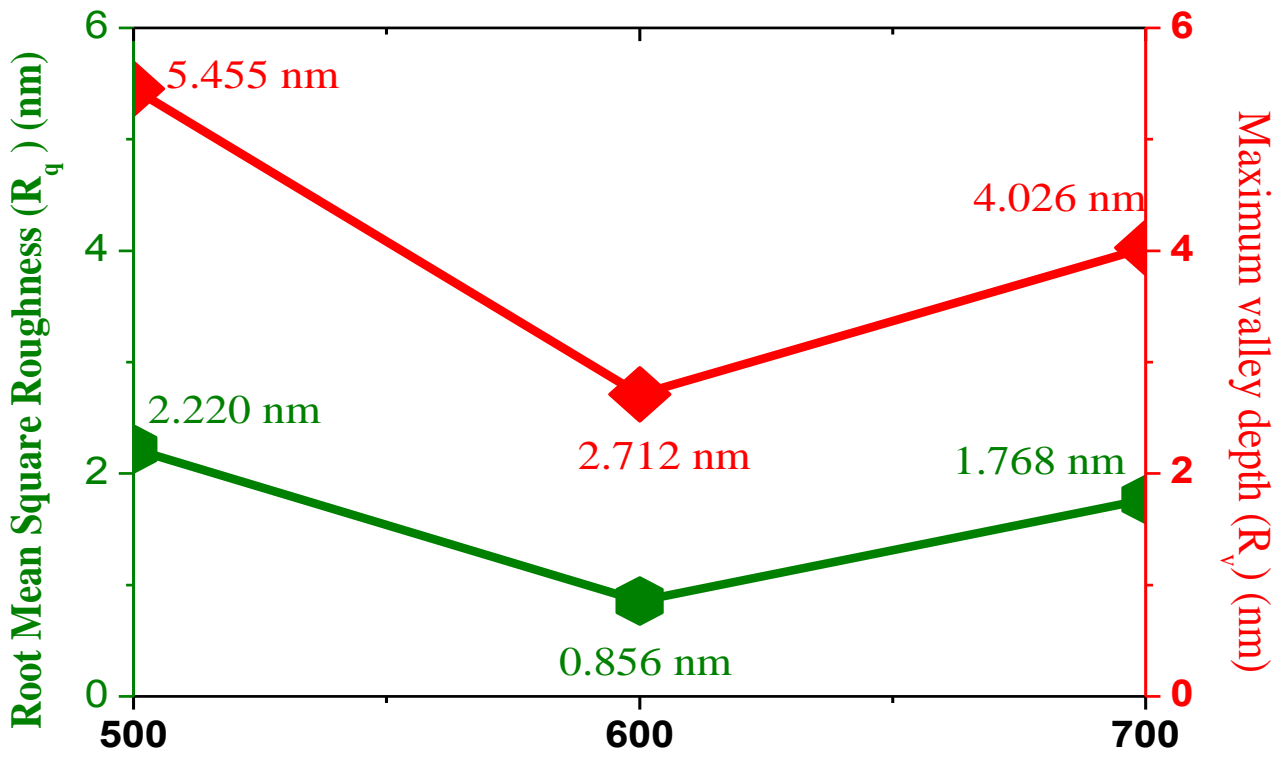

Substrate Temperature $\left(\mathrm{C}^{\mathrm{O}}\right)$

Figure 4. Root Mean Square Roughness and Maximum valley depth versus substrate temperature.

\subsection{SEM analysis}

Figure 5 gives SEM images of $\operatorname{InGaN} / G a N / p-S i$ thin films for different substrate temperature growth condition. Before taking measurements, it was covered our sample with $5 \mathrm{~nm}$ gold. The reason for doing this is to prevent the accumulation of excess electron on thin film surface and is good conductivity of gold. In growth condition of $500{ }^{\circ} \mathrm{C}$ substrate temperature, InGaN thin film surface shows almost homogeneous and granular structure with few agglomerations on surface. These agglomerations can be related to Van-der waals forces between particle. Past study shows indium aggregation at In GaN/GaN multiple quantum wells resulted in InGaN mounds, forming localized states for trapping carriers. Thus; increased indium aggregation could improve luminescence efficiency [18]. When substrate temperature is increased from $500{ }^{\circ} \mathrm{C}$ to $600{ }^{\circ} \mathrm{C}$, thin film surface still shows almost homogeneous and granular and nano-structure but with more agglomerations on surface. When substrate temperature is increased from $600{ }^{\circ} \mathrm{C}$ to $700{ }^{\circ} \mathrm{C}$, thin film surface displays dislocations on the surface. They are separated from each other in the form of islets and surface structure of the thin film is distorted. Literature work shows that dislocations could contribute to relaxation of InGaN / GaN quantum dots [19]. Consequently, increasing substrate temperature worsened the surface structure of InGaN thin film. Substrate temperature has been found to have an effective role in the surface structure of InGaN thin film. These results are consistent with XRD results. 

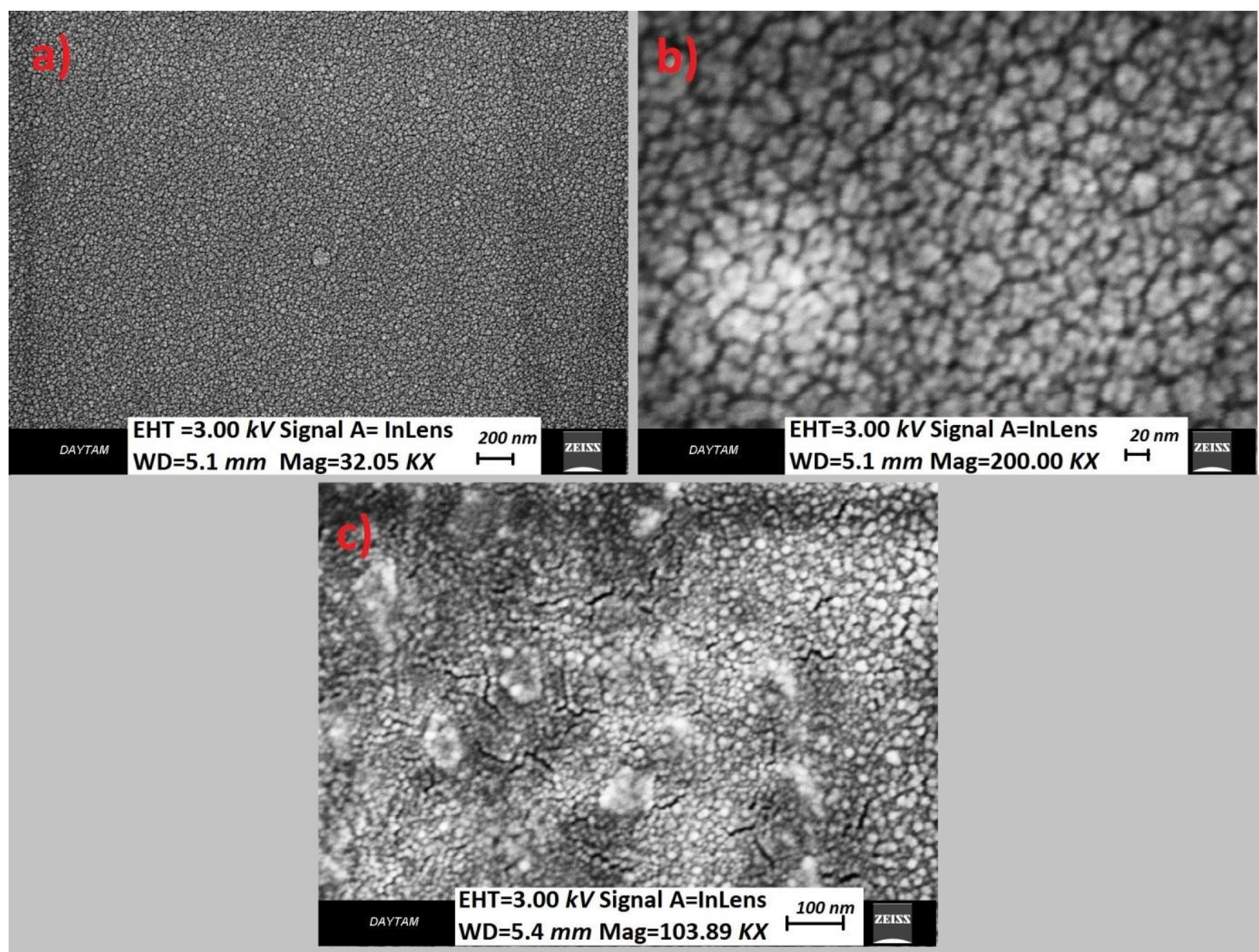

Figure 5. SEM images of InGaN/GaN/p - Si thin films for a) $500^{\circ} \mathrm{C} \mathrm{b)} 600^{\circ} \mathrm{C}$ c ) $700{ }^{\circ} \mathrm{C}$ substrate temperature growth condition.

\subsection{XPS analysis}

X-ray photoelectron spectroscopy (XPS) is the experimental method used for the analysis of the surface chemistry of the sample to be measured. This method is capable of measuring chemical state, the formula, composition, electronic state of element. XPS survey spectrum of $\operatorname{InGaN} / \mathrm{GaN} / p-\mathrm{Si}$ thin film is given in Figure 6. From our survey spectrum, we had twelve photoelectron peaks following elements-core levels; $G a 2 p, G a 2 p, C K L L$ (Auger electron energies of the elements, KLL transtion), In $3 p, O 1 s$, In $3 d$, Ga LMM (Auger electron energies of the elements, LMM transition), $N 1 s, C 1 s, G a 3 s, G a 3 p, G a 3 d$ In $4 d$. The corresponding binding energies are $1146 \mathrm{eV}, 1119 \mathrm{eV}$, $979 \mathrm{eV}, 666 \mathrm{eV}, 533 \mathrm{eV}, 446 \mathrm{eV}, 425 \mathrm{eV}, 398 \mathrm{eV}$, $286 \mathrm{eV}, 163 \mathrm{eV}, 106 \mathrm{eV}, 21 \mathrm{eV}$, respectively. Literature study supported our values that found [20]. XPS parameters of InGaN thin film can be found in Table 5 . In this table, it has been seen $O 1 s$ and $C 1 s$ at \% 1.563 and \% 5.077 as elemental. The reason why carbon and oxygen are seen in our thin film can be explained as follows. No matter how much vacuum we do in our chamber (in our system), we will always have oxygen and carbon in it and expect it to be a certain amount in our film. XPS result is in good agreement by XRD result. 


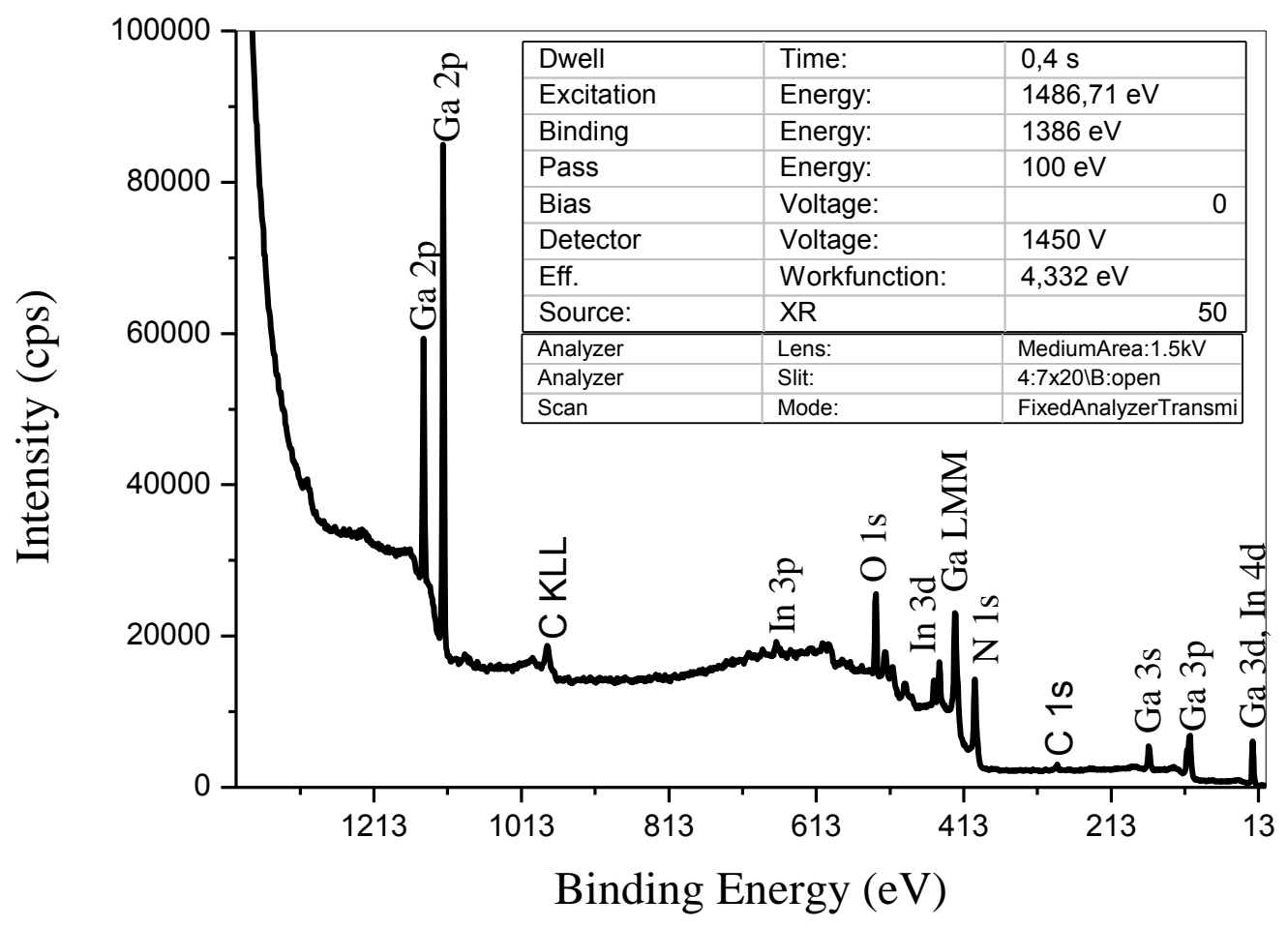

Figure 6. XPS survey spectrum of InGaN/GaN $/ p-S i$ thin film.

Table 5. XPS parameters of $I n G a N / G a N / p-S i$ thin film produced.

\begin{tabular}{ccccc}
\hline Name & Position & FWHM & Area & At \% \\
\hline In 3d & 532.00 & 2.842 & 1853.7 & 20.251 \\
N 1s & 398.00 & 3.844 & 2699.4 & 48.004 \\
Ga 3d & 21.00 & 2.500 & 854.9 & 25.105 \\
O 1s & 446.00 & 2.703 & 1098.6 & 1.563 \\
C 1s & 286.00 & 3.349 & 158.6 & 5.077 \\
\hline
\end{tabular}

\section{Conclusion}

InGaN thin films at hexagonal structure were successfully grown onto the $G a N / p-S i$ substrate. XRD results confirm that better crystallizing in structure of $\operatorname{InGaN} / \mathrm{GaN} / \mathrm{p}-\mathrm{Si}$ thin film has been achieved under $500{ }^{\circ} \mathrm{C}$ substrate temperature and worse crystallizing (which means amorphous phase) in structure of InGaN/ $\mathrm{GaN} / p-S i$ thin film has been achieved under $700^{\circ} \mathrm{C}$ substrate temperature. It was concluded that all of materials have compressive stress due to thermal expansion coefficient difference, difference of lattice parameters, impurities and defects. It was shown that, except for $700^{\circ} \mathrm{C}$ substrate temperature growth condition, AFM images presented the periodic arrangement of grain with almost homogeneous, Nanostructured InGaN thin films surface. Also, it was reached the conclusion that morphological parameters of InGaN thin film show non-linear variation with substrate temperature. It was realized that in growth condition of $500{ }^{\circ} \mathrm{C}$ substrate temperature, InGaN thin film surface shows almost homogeneous and granular structure with few agglomerations on surface due to Van-der waals forces between particles. In growth condition of $700^{\circ} \mathrm{C}$ substrate temperature, thin film surface displays dislocations on the surface, which are separated from each other in the form of islets and surface structure of the thin film is distorted. This is supported and compatible with XRD results. XPS results gives twelve photoelectron peaks following elements-core levels; Ga $2 p, G a 2 p, C K L L$ (Auger electron energies of the elements, KLL transtion), In $3 p, O$ 1s, In $3 d$, Ga LMM (Auger electron energies of the elements, LMM transition), $N 1 s, C 1 s, G a 3 s, G a 3 p, G a 3 d$ In $4 d$. XPS analysis shows few amount of carbon and oxygen is seen in our thin film, which is originated inevitably from growth process. As the main result, detailed morphological and structural parameters of InGaN thin 
films can be controlled with playing with substrate temperature, which is proves that substrate temperature is crucial role on growth of InGaN thin film. It was inferred that this result can be important to produce better quality InGaN based optoelectronic device.

\section{Acknowledgement}

This work was supported by Muş Alparslan University Scientific Research Coordination Unit. Project Number: BAP-18FEF-4901-03.

\section{Author's Contributions}

Asim Mantarcı: Drafted and wrote the manuscript, performed the experiment and result analysis, supervised the experiment's progress, result interpretation, did all the research and analysis.

\section{Ethics}

There are no ethical issues after the publication of this manuscript.

\section{References}

1. Mantarcı, A, Kundakçı, M. 2019. Physical properties of RF magnetron sputtered $\mathrm{GaN} / \mathrm{n}$-Si thinfilm: impacts of RF power. Optical and Quantum Electronics; 51:81

2.Mantarcı, A, Kundakçı, M. 2017. Some of structural and morphological optimization of $\mathrm{GaN}$ thin film on $\mathrm{Si}(100)$ substrate grown by RF sputter. AIP Conference Proceedings;, 1833:020119.

3.Kundakçı, M, Mantarcı, A, Erdoğan, E. 2017. Growth and characterization of $\mathrm{GaN}$ thin film on $\mathrm{Si}$ substrate by thermionic vacuum arc (TVA). Materials Research Express; 4:016410.

4. Duan, X, Zhang, J, Wang, S, Quan, R, Hao, Y. 2017. Effect of graded InGaN drain region and 'In' fraction in InGaN channel on performances of InGaN tunnel field-effect transistor. Superlattices and Microstructures; 112:671-679.

5. Zhang, J, Wang, X, Liu, J, Mo, C, Wu, X, Wang, G, Jiang, F. 2018. Study on Carrier transportation in InGaN based green LEDs with V-pits structure in the active region, Optical Materials; 86:46-50.

6. Mantarc1, A, Gündüz, B. 2016. A study on refractive index dispersion and optoelectronic parameters of the BCzVB OLED material by using solution method. Optical and Quantum Electronics; 48:547.

7. Itoh, T, Hibino, S, Sahashi, T, Kato, Y, Koiso, S, Ohashi, F, Nonomura, S. 2012. InXGa1-XN films deposited by reactive RFsputtering. Journal of Non-Crystalline Solids; 358: 2362-2365.

8. Erdoğan, E, Kundakçı, M, Mantarcı, A. 2016. InGaN thin film deposition on Si (100) and glass substrates by termionic vacuum arc, in: Journal of Physics: Conference Series; IOP Publishing, pp. 012019.

9. Kuo, D, Tuan, T, Li, C, Yen, W. 2015. Electrical and structural properties of $\mathrm{Mg}$-doped InxGa1-xN $(\mathrm{x} \leq 0.1)$ and $\mathrm{p}-\mathrm{InGaN} / \mathrm{n}-\mathrm{GaN}$ junction diode made all by $\mathrm{RF}$ reactive sputtering. Materials Science and Engineering: $B ; 193: 13-19$

10. Tuan, T, Kuo, D, Lin, K, Li, G. 2015. Temperature dependence of electrical characteristics of $\mathrm{n}-\mathrm{InxGa1}-\mathrm{xN} / \mathrm{p}-\mathrm{Si}$ hetero-junctions made totally by RF magnetron sputtering. Thin Solid Films; 589:182 187.

11. Diale, M, Auret, F, . Odendaal, R, Roos, W. 2005. Analysis of GaN cleaning procedures, Applied Surface Science. 246:279-289.
12. López-Apreza, E, Arriaga, J, Olguín, D. 2010. Ab initio calculation of structural and electronic properties of alloys. Revista mexicana de fisica; 56:183-194.

13. Kisielowski, C, Krüger, J, Ruvimov, S, Suski, T, Ager, J, Jones, E, Liliental-Weber, Z, Rubin, M,. Weber, E, Bremser, M, Davis, R. 1996. Strain-related phenomena in $\mathrm{GaN}$ thin films. Physical Review B; 54:17745-17753.

14. Jian, S, Fang, T, Chuu, D. 2006. Nanomechanical characterizations of InGaN thin films. Applied Surface Science; 252:3033-3042.

15. Moon, M, Chung, J, Lee, K, Oh, K, Wang, R, Evans, A. 2002. An experimental study of the influence of imperfections on the buckling of compressed thin films. Acta Materialia; 50:1219-1227.

16. Li, J, Tang, Y, Li, Z, Ding, X, Li, Z. 2017. Study on the optical performance of thin-film light-emitting diodes using fractal microroughness surface model. Applied Surface Science; 410:60-69.

17. Demir, M, Yarar, Z, Ozdemir, M. 2013. Effect of polarization and interface roughness on the transport properties of $\mathrm{AlGaN} / \mathrm{GaN}$ heterostructure. Solid State Communications; 158:29-33.

18.You, Y, Feng, S, Wang, H, Song, J, Han, J. 2017. The effects of indium aggregation in $\mathrm{InGaN} / \mathrm{GaN}$ single and multiple quantum wells grown on nitrogen-polar GaN templates by a pulsed metalorganic chemical vapor deposition. Journal of Luminescence; 182:196-199.

19. Yang, D, Wang, L, Hao, Z, Luo, Y, Sun, C, Han, Y, Xiong, B, Wang, J, Li, H. 2016. Dislocation analysis of InGaN/GaN quantum dots grown by metal organic chemical vapor deposition. Superlattices and Microstructures; 99:221-225.

20. Lisowski, W, Grzanka, E, Sobczak, J, Krawczyk, M, Jablonski, A, Czernecki, R, Leszczyński, M, Suski, T. 2014. XPS method as a useful tool for studies of quantum well epitaxial materials: Chemical composition and thermal stability of InGaN/GaN multilayers. Journal of Alloys and Compounds; 597:181-187. 